NBER WORKING PAPER SERIES

\title{
THE IMPACT OF PATIENT COST-SHARING ON THE POOR: EVIDENCE FROM MASSACHUSETTS
}

\author{
Amitabh Chandra \\ Jonathan Gruber \\ Robin McKnight \\ Working Paper 18023 \\ http://www.nber.org/papers/w18023
NATIONAL BUREAU OF ECONOMIC RESEARCH
1050 Massachusetts Avenue
Cambridge, MA 02138
April 2012

We are grateful to Kaitlyn Kenney and the staff at the Massachusetts Health Connector for making these data available. We thank, without implicating, Dan Fetter, Ilyana Kuziemko, and Joseph Newhouse for very helpful suggestions on earlier versions of this paper. The views expressed herein are those of the authors and do not necessarily reflect the views of the National Bureau of Economic Research.

At least one co-author has disclosed a financial relationship of potential relevance for this research. Further information is available online at http://www.nber.org/papers/w18023.ack

NBER working papers are circulated for discussion and comment purposes. They have not been peerreviewed or been subject to the review by the NBER Board of Directors that accompanies official NBER publications.

(C) 2012 by Amitabh Chandra, Jonathan Gruber, and Robin McKnight. All rights reserved. Short sections of text, not to exceed two paragraphs, may be quoted without explicit permission provided that full credit, including $(\subset$ notice, is given to the source. 
The Impact of Patient Cost-Sharing on the Poor: Evidence from Massachusetts Amitabh Chandra, Jonathan Gruber, and Robin McKnight

NBER Working Paper No. 18023

April 2012

JEL No. I13

\begin{abstract}
$\underline{\text { ABSTRACT }}$
Greater patient cost-sharing could help reduce the fiscal pressures associated with insurance expansion by reducing the scope for moral hazard. But it is possible that low-income recipients are unable to cut back on utilization wisely and that, as a result, higher cost-sharing will lead to worse health and higher downstream costs through hospitalizations. We use exogenous variation in the copayments faced by low-income enrollees in the Massachusetts' Commonwealth Care program to study these effects. We estimate separate price elasticities of demand by type of service (hospital care, drugs, outpatient care). Overall, we find price elasticities of about -0.15 for this low-income population - fairly similar to elasticities calculated for higher-income populations in other settings. These elasticities are somewhat larger for the chronically sick and older enrollees. A substantial portion of the decline in utilization comes from some patients cutting back on use completely, but we find no (detectable) evidence of offsetting increases in hospitalizations or emergency department visits in response to the higher copayments, either overall or for the chronically ill in particular.
\end{abstract}

\author{
Amitabh Chandra \\ John F. Kennedy School of Government \\ Harvard University \\ 79 JFK Street \\ Cambridge, MA 02138 \\ and NBER \\ amitabh_chandra@harvard.edu \\ Jonathan Gruber \\ MIT Department of Economics \\ E52-355 \\ 50 Memorial Drive \\ Cambridge, MA 02142-1347 \\ and NBER \\ gruberj@mit.edu
}

\author{
Robin McKnight \\ Department of Economics \\ Wellesley College \\ 106 Central Street \\ Wellesley, MA 02481 \\ and NBER \\ rmcknigh@wellesley.edu
}


The recently enacted Patient Protection and Affordable Care Act (PPACA) includes the largest expansion of health insurance coverage to low-income populations in our nation's history. The Federal government will spend almost $\$ 1$ trillion over the next decade to subsidize insurance for those below 400\% of the Federal Poverty Line (FPL). Roughly, half that total will be through expansions of the Medicaid program, which will provide publicly financed health care for those below $133 \%$ of the poverty line at essentially zero patient cost. The other half will be in the form of subsidies to private insurance for those between 133 and 400 percent of the poverty line. These subsidies are of two types: the first type is premium subsidies, which offset the premium cost of insurance by limiting the percentage of income that low-income individuals must pay. The second type is cost-sharing subsidies, which offset to some extent the copayments, coinsurance and deductibles that these low-income populations face.

The motivation for the subsidies is twofold: to make the transfers in PPACA more progressive, and to protect low-income populations from sacrificing necessary medical care because of cost. The optimal level of such subsidies, therefore, depends critically on the way in which the medical care utilization of low-income groups responds to cost sharing, and how any change in utilization impacts their health. On one hand, greater patient cost-sharing could help reduce the fiscal pressures associated with insurance expansion by reducing the scope for moral hazard. But on the other, it is possible that low-income recipients are unable to cut back on utilization wisely and, consequently, there remains a concern among many that higher costsharing on primary care will lead to less effective use of primary care, worse health, and higher downstream costs at hospitals (called “offset effects”). Commentators such as Evans et al. (1993) have argued that user fees are a “policy zombie,” while Donaldson (2008) argued that it is "wrong, unfair, and ineffective to try to limit consumer and patient access through user fees, and also to dress up this process as actually enhancing access.”

Most analyses of this issue still rely on the evidence from the RAND Health Insurance Experiment (HIE) of the mid-1970s (Newhouse 1993). This seminal study found that, for the population as a whole, there was a significant but modest response of medical care utilization to the point-of-service cost of medical care. The reductions in care appeared to come across the board, both in categories of "effective” and "ineffective” medical care. There were, however, no "offset” effects in terms of reduced primary care leading to a demand for more hospital care; indeed, reduced primary care appeared to lower spending on hospital care. Furthermore, most 
importantly, there was no evidence of a detrimental effect on the typical person in terms of worsened health. That is, for the average person in the HIE, there did not appear to be productive returns to marginal health care utilization in terms of improving health status.

Although the sample size was more limited, the HIE did separately examine subgroups by income and health. For the subset of low-income population, the findings paralleled those for the larger population: a modest impact on health care spending, with no offset effects and no impact on health status. However, there was an important potential exception to this finding: for the chronically ill low-income population, there was a suggestion of a sizeable rise in blood pressure for those in the higher cost-sharing insurance plan (although the overall health results for this population were mixed, and the blood pressure result itself was not significant). In the years since the HIE, there has been relatively little research on the impacts of cost-sharing on low-income populations. But the HIE evidence is now over thirty years old, and changes in the practice of medicine-including greater reliance on managed care contracts, increased use of prescription drugs, the growth of imaging and diagnostic technology, and the development of minimally invasive surgery-may imply a structural change in the elasticity of medical demand and the health impacts of any utilization reductions.

The possibility of offset effects is real: in our earlier work (Chandra, Gruber and McKnight 2010a), we examined this question in a contemporary setting, and found evidence of hospitalization offsets in elderly who had been diagnosed with chronic diseases such as diabetes, hypertension, and hyperlipidemia. Tamblyn et al (2001) examined the effect of cost-sharing on prescription drugs in the poor and found a 13 percent increase in the probability of hospitalization, nursing home admission, or mortality. Similarly, Hsu et. al (2006) found that a cap on drug benefits was associated with lower drug consumption and poorer adherence poorer control of blood pressure, lipid levels, and glucose levels. The key role of cost-sharing in the PPACA suggests the importance of revisiting this topic in a low-income population.

In this paper, we use exogenous variation in the copayments faced by low-income enrollees in the Massachusetts' Commonwealth Care program. This state program was the model for PPACA, providing highly subsidized insurance for families below $300 \%$ of the poverty line. Importantly, there was a substantial increase in the copayments paid by enrollees in this program at open enrollment in July 2008 that we exploit for identification. Using unique claims data on the Commonwealth Care population provided to us by the state, we are able to estimate separate 
price elasticities of demand by type of service (hospital care, drugs, outpatient care, etc.), and examine the effect of greater cost-sharing on utilization and hospitalization offsets.

In previous work (Chandra, Gruber and McKnight, 2010b), we had provided preliminary evidence on the elasticity of demand in this population, using only the first six months of postpolicy change data. This paper extends that analysis by incorporating additional post-policy change data, by using a superior estimation framework, and most importantly by considering a variety of questions not addressed in that earlier paper, such as the issue of population heterogeneity in demand elasticities and in offset effects. We are also able to perform a number of specification checks that provide assurance that our results aren't be driven by stockpiling (where patients avail of medical care immediately before the policy change and do not use care in the immediate months after), or the other confounders that may be timed with the policy change. As a result of a variety of improvements to our data and estimation, our current estimate for the overall price elasticity of demand in this population is on the low end of the range of elasticities that we reported in our earlier work. Overall, we find price elasticities of about -0.15 for this low-income population, which is similar to, but somewhat lower than, elasticities calculated for higher-income populations in other settings. In addition, we find no evidence of offsetting increases in hospitalizations or emergency department visits in response to the higher copayments, even among the chronically ill population.

Our paper proceeds as follows. Section 1 provides background on the institutional setting and data. Section II presents our estimation strategy. Section III shows our results, while Section IV presents a set of robustness checks of those findings. Section V concludes with a discussion of the implications of our findings.

\section{Institutional Setting and Data}

Our analysis focuses on the implications of greater patient cost-sharing that was imposed on low-income adults (aged 19 to 64) in the Commonwealth of Massachusetts. Most of these persons were beneficiaries of Massachusetts’ insurance expansion, which was signed into law on April 12, 2006. Its goal was to achieve near-universal coverage of the Massachusetts population by providing legal residents earning up to $150 \%$ of the FPL completely subsidized coverage and 
large premium subsidies to those earning over $150 \%$ of the FPL and below $300 \%$ of the FPL. ${ }^{1}$ These programs are offered by a subsidized program known as Commonwealth Care (henceforth, CommCare) to persons who are not offered employer-provided health insurance, to those who cannot be dependents on another person's family plan, and to those who do not qualify for other public health insurance programs such as Medicaid. Currently, the monthly enrollee premium for CommCare is \$0 if the member's income is below 150\% of the FPL, \$39 for income between 150 and 200 percent of the FPL, \$77 for those between 200 and 250 percent of the FPL, and \$116 for those between 250 and 300 percent of the FPL.

Members are eligible for different plan types based on where their income is relative to the FPL, and each plan type offers a different level of patient cost-sharing. From October 2006 to June 2008, there were four different plans_ - each with the same benefits but with different levels of patient cost-sharing. The cost-sharing provisions generate discontinuities in cost-sharing at 100 and 200 percent of the FPL. For members whose incomes were between 200 and 300 percent of the FPL, there were two plan types: Plan 3 features higher cost-sharing, but lower monthly premiums, while Plan 4 features lower cost-sharing, but higher monthly premiums. Plan 4 was discontinued in July 2008 and its members were placed into Plan 3. Consequently, this group incurred a substantial increase in patient cost-sharing as a result of the elimination of Plan 4.

\section{Data}

For the purposes of this analysis, Massachusetts' Commonwealth Health Insurance Connector Authority provided us with the universe of (de-identified) enrollment and claims data from July 2007 through June 2009. This sample period covers a full year before and a full year after the copayment change that we are studying. From the enrollment file, we can observe the CommCare plan in which each individual was enrolled in each month of the sample period. We also observe very basic demographic information, such as age and gender. For most individuals, we observe household income as a share of the FPL, although this information is missing for some individuals. As a result of this missing information, we must exclude $25 \%$ of member-

\footnotetext{
${ }^{1}$ In 2009, $150 \%$ of the FPL is $\$ 16,620$ for an individual; $\$ 33,084$ for a family of four. $300 \%$ of FPL is $\$ 32,508$ for an individual; $\$ 66,168$ for a family of four. These are national cutoffs (Kaiser Commission on Medicaid and the Uninsured, 2009).
} 
months from the full sample. Because income information is disproportionately missing for individuals who were enrolled for shorter periods of time, this restriction affected only $16 \%$ of the member-months in the continuously enrolled subsample that is the focus of our analysis. We also exclude 10,073 member-months that report income levels above 300\% of FPL and 19,290 member-months that report ages below 19 or above 65, since these individuals should not be eligible for CommCare. After making these adjustments, our full sample includes 2,842,492 member-month observations and our continuously enrolled subsample includes 1,866,212 member-month observations.

Our claims data include the universe of medical claims for CommCare enrollees during our sample period. For each member in each month of our data, we use the claims data to calculate the sum of all spending for each type of medical care, including zeroes for members who have no claims in a particular month. ${ }^{2}$ For our regression analysis, we then collapse these member-month observations to averages for each percent of income as a share of the FPL in each of the 24 months of data. We allow two observations per month for income cells between 200 and 300 percent of FPL: one for individuals who were ever enrolled in Plan 4 and one for individuals who were never enrolled in Plan 4. As a result, the sample size for our main regressions is 9,644 .

\section{Descriptive Statistics}

In Table 1, we describe the characteristics of our study population and, in Table 2, we provide details of the copayment change. As Table 1 illustrates, the sample is poor; on average, members were at 95\% of the FPL. They are also quite sick, with over 30\% of the sample having some form of chronic disease (as measured by a diagnosis of diabetes, hypertension, hyperlipidemia, asthma, arthritis, affective orders, or gastritis - conditions that are derived from Goldman et al. (2007) and also used in Chandra, Gruber and McKnight (2010a)). Annual spending is approximately $\$ 4,600$, much of which comes from hospitalizations and outpatient care.

\footnotetext{
${ }^{2}$ In our earlier work, we computed average monthly utilization for each individual over the months during which they were enrolled and then computed an average across all individual-years. In this version, we simply compute the average of monthly utilization across all member-month observations. In effect, we previously placed disproportionate weight on individuals who were enrolled for shorter periods of time; now the weight that we place on individuals is proportional to the amount of time that they are enrolled.
} 
In our data, we identify outpatient care as care that indicates "outpatient hospital” as the place of service on the claim; it includes both facility and professional claims for the outpatient hospital visit. Such care accounts for about $20 \%$ of total costs. Labs include any claims that indicate "Independent Laboratory" as the place of service, or that indicate that the service provided was "Laboratory” or "Radiology." Labs account for approximately 15\% of total costs. Office visits include professional claims that do not indicate that the place of service is outpatient hospital, independent laboratory, or emergency room; that do not occur on the same day as any inpatient hospital claims; and that do not have a service code of "Laboratory" or "Radiology." They are, therefore, largely ambulatory visits for checkups and consultations and they account for roughly $15 \%$ of total costs.

In Table 1, we report means for two samples: the full sample with 247,565 members and a sample of 122,528 members who stayed continuously enrolled at the time of the copayment increase. Individuals in this second "continuously enrolled" sample were not necessarily enrolled for the full 24-month sample period, but did not change their enrollment status at the time of the copayment increase. Individuals who initially enrolled in Plan 4 but switched to Plan 3 in July 2008 are not excluded from the "continuously enrolled" sample, since it was not possible for them to remain in Plan 4 at that time.

We created this "continuously enrolled" sample because examining utilization changes in the full-sample is subject to considerable bias if member income or enrollment is a function of health status. This is a real concern in the full sample: in our work on the individual mandate in Massachusetts (Chandra, Gruber, McKnight, 2011), we demonstrated that the insurance market for Commonwealth Care was laced with adverse selection prior to the individual mandate binding on January 1, 2008. Consistent with adverse selection, we found that those who enrolled first in CommCare were sicker, with relatively healthy individuals joining the plan closer to the date of the mandate. This time-varying change in the composition of enrollees will affect fullsample estimates of the price elasticity of demand because utilization and health-status are correlated in a time varying manner. Moreover, there was a change in the premiums charged enrollees in Commonwealth Care at the same time that copayments changed, which could impact the composition of enrollees. To mitigate these concerns, we examine the continuously enrolled sample, who were continuosuly enrolled just before and after the policy change, to ensure that our findings are not the result of differential entry and exit rates for different types of individuals 
around the time of the copayment change. Comparing the means in Table 1 reassures us - the two samples are similar in age, gender, and income; furthermore, utilization levels are similar as are enrollments across the four plans that we study. ${ }^{3}$

In Table 2 we summarize the variation that we use to understand the effect of patient cost-sharing on patient demand: we exploit a series of changes in the discontinuities in the costsharing provisions of CommCare that occurred in July 2008. These changes, which varied by type of plan, are reported in Table 2. Of these changes, the most salient are the increases in copayments for prescription drugs and office visits for members whose incomes exceeded 100\% of the FPL. Copayments for ER visits increased only for those with incomes over 200\% of FPL. Copayments for hospital admissions were unchanged, except for the Plan 4 members who had to switch to Plan 3. Note that there were no copayment changes for members whose income was between 0 and 100 percent of the FPL.

In order to estimate the price elasticity of demand, we devise a simple measure of the overall change in copayments. Specifically, we calculate the weighted average of the copayments for generic drugs, formulary drugs, non-formulary drugs, office visits, ER visits, and hospitalizations. The weights are average monthly utilization of each type of care during the preperiod (July 2007 to June 2008) for the entire sample. At the bottom of Table 2, we summarize the (unadjusted) change in copayments that we will exploit: that is, there is no change for Plan 1 , a 51\% increase for Plan 2, a 23\% increase for Plan 3, and a 97\% increase for Plan 4.

In Figure 1, we plot the average copayment for one category of utilizationgeneric drugs - by income category and by period ('pre' denotes the period before July 2008 and 'post' denotes the period after July 2008). This figure graphically illustrates the basis for our formal regression analysis below.

Because a number of cost-sharing increases occurred at the same time, it is important not to attribute changes in a specific category of spending, such as the utilization of prescription drugs, solely to changes in the copayments for these drugs. Declines in the use of prescription

\footnotetext{
${ }^{3}$ We investigated the possibility that a disproportionate number of people switched plans because of the copayment increase. The percent of members who were new members of a plan in May, June, July and August of 2008 was 5.2, 5.2, 4.7 and 4.4 percent respectively (the policy change occurred in July 2008). Similarly, the percent of members who left the plan in May, June, July and August of 2008 was 5.2, 4.8, 4.7 and 5.7 percent respectively. In other words, we do not see excess churning at the time that the policy change occurred.
} 
drugs may, for example, partially reflect a reduction in the use of office visits. For this reason, we are most interested in the reduction in total expenses across all categories of care.

\section{Estimation}

Because the policy variation occurs at the level of plans, and plans are defined according to the percent of FPL of the member's income, we estimate our regression models at the level of FPL $x$ month, and cluster our standard errors at the level of FPL. The simplest framework to think about estimating the price elasticity of demand is with the equation below:

$$
\ln \text { Spending }_{j t}=\beta_{0}+\beta_{1} \ln \text { Copayment }_{j t}+F P L_{j}+\text { Time }_{t}+\varepsilon_{j t}
$$

Here, Spending ${ }_{j t}$ is the average spending for income cell $j$ in time $t$, and Copayment ${ }_{j t}$ is the average copayment for this cell at a point in time. Income is defined as percent of the FPL so all our specifications can (and do) include fixed effects for each percent of FPL. Note that plan fixed effects are perfectly correlated with the percent of FPL fixed effects, and are therefore not included. We also include year x month fixed effects to remove any effects of time trends or seasonality.

Equation (1) identifies the price (copayment) elasticity of healthcare as $\beta_{1}$. In equation (1) variation in copayments is coming only from within-plan increases. Our approach is identical to identifying the effect of copayment changes using a regression-discontinuity design, where we identify off changes in copayments at 100 and 200 percent of the poverty line (see Figure 1); later in this paper (Table 7), we restrict the analysis to utilization in the period immediately around the policy change and demonstrate that the results are unchanged.

We could estimate equation (1) with OLS, but this would make sense only in a world where all cells had non-zero spending. It is tempting to add a small amount of (arbitrary) spending, such as $\$ 1$, to overcome the problem that $\ln (0)$ is not defined; indeed, this is the approach that we took in Chandra, Gruber, McKnight (2010b). But this can be a problematic strategy, because $\ln$ (Spending) is quite sensitive to spending at the bottom of the spending distribution; converting $\ln (\$ 1)$ to $\ln (\$ 2)$ has the same effect as converting $\ln (\$ 1000)$ to $\ln (\$ 2000)$. To circumvent this problem, we follow the literature and estimate a general linear model with a log-link function (Buntin and Zaslavsky, 2004). In GLM models with a log link-function, the conditional mean is modeled as: 
This setup models both the mean and variance on the original scale of the dependent variable (here, dollars). We allow for a natural form of heteroscedascitiy, were var(Spending $\mid X)$ is allowed to depend on the mean level of conditional spending, $\mathrm{E}($ Spending $\mid \mathrm{X})$, which is a function of the covariates. The use of the GLM model avoids the problem with two-part models (which introduce selection on the dependent variable) and yields estimates that are easily interpretable as elasticities. ${ }^{4}$ In principal, equation (2) could also be estimated at the level of individuals and we could include individual fixed-effects. Because the policy change occurs at the plan level, and individuals are assigned to plans based on their income, there is no additional benefit from this approach.

\section{Results}

Table 3 reports our key results. In column 1, we report the overall elasticity, which is -0.15; a 10 percent increase in prices faced by patients would reduce utilization by 1 to 2 percent. This is comparable to the much older estimates of RAND HIE, albeit somewhat lower

With our data, we are able to estimate separate effects by type of service: hospital spending, ER spending, outpatient spending, office visit spending, prescription drug spending, and spending on laboratory services. We are also able to examine whether there were 'offset' effects; that is, did inpatient hospital and emergency department visits increase, potentially because of excessive reductions in primary care utilization? The results in Table 3 demonstrate that spending on hospital care, and ER are price inelastic at conventional spending levels. Relatively more discretionary services exhibit larger elasticies: elasticities for laboratory services and outpatient care are almost twice as large, but still small.

Perhaps most interestingly, we find no evidence of offset effects. Hospital and ER utilization fall, not rise, as copayments are increased (but these effects are statistically

\footnotetext{
${ }^{4}$ In contrast to this model, in OLS one is assuming that $\mathrm{E}(\ln$ Spending $\mid \mathrm{X})=\beta_{0}+\beta_{1} \ln$ Copayment $_{j t}+\mathrm{FPL}_{j}+$ Time $_{t}$, which is difficult to translate into easily interpretable statements about E(Spending). The solution is to use a 'smearing' estimator, where exponentiated predictions are multiplied by a smearing factor to calculate expected values on the raw (unlogged) scale (Manning et.al, 1987).
} 
insignificant). For Plans I, II and III, hospital copayments did not increase, so that any impact on hospital utilization represents a pure offset effect. But for patients in Plan IV, this could reflect the demand side impact of copayments rising from $\$ 50$ to $\$ 250$ for hospital care. Our results are similar, however, if we exclude Plan IV (which is unsurprising since Plan IV is 1 percent of the total sample), clarifying that we are estimating the offset effect only.

In Table 4, we examine whether the overall elasticity varies by type of patient. We first examine whether price sensitivity varies with health status, as measured by the Charlson Comorbidity Index. The Charlson Index is a weighted sum of indicators for certain health conditions, where the weights indicate the relative increase in one-year mortality risk associated with the condition, as described in Charlson et al. (1987). We report separate price elasticities for individuals with a Charlson index value of 0 (i.e., those who have none of the conditions) and for those with Charlson index values of 1 or greater (this is the sickest 18 percent of our population). We also consider variation in price elasticities by gender and age group.

The results in Table 4 indicate very comparable elasticities across health (Charlson index) groups and across genders. There is a somewhat higher elasticity for the chronically ill. We also find larger price elasticities for older enrollees. The results therefore suggest that those facing the highest expenditure risk appear to be the most price sensitive with respect to copayments.

We are particularly interested in considering the presence of offset effects amongst those who are chronically sick: this is the group for whom we found hospitalization offsets in the elderly (Chandra, Gruber, McKnight, 2010a). In Table 5, we restrict the analysis to members with a Charlson score of 1 or more (which is the sickest 18 percent of the population). Even in this sample, we do not see evidence of hospital or ER spending increasing as a result of copayments increasing, although our category-specific estimates are fairly imprecise.

There are two mechanisms behind the reduced utilization. Some members cut back on the service completely (extensive margin), while others reduce their utilization while continuing to use some care (intensive margin). These two effects are combined in the tables that we have reported so far. In Table 6, we report the importance of the extensive margin for all patients. Here, the dependent variable is the fraction of members who had any utilization of care, by type of care; this can modeled by OLS. We see statistically insignificant, negative effects on the extensive margin of hospital care, emergency room care, and outpatient care. But a 10\% increase in copayments results in a 2.7 percentage point decline in the probability of making any 
physician office visits, a 6.7 percentage point decline in the use of any prescription drugs, and a 3.2 percentage point decline in the use of any laboratory services. These results are very consistent across samples.

We can ask how much of the overall decline in utilization is plausibly the consequence of patients reducing utilization at the extensive margin. To perform this calculation, we multiply the change in the margin of participation at the extensive margin with the spending among those who adjusted on the extensive margin, and then divide by the total spending. We proxy utilization for those who adjusted on the extensive margin by using the average utilization of patients who had positive utilization . ${ }^{5}$ For example, for total spending, we calculate the implied elasticity from behavior at the extensive margin as $-0.050 \times \$ 788$ / \$358.8 $=-0.12$ (here, $\$ 788$ is the average spending of enrollees with non zero spending, and \$358.8 is average spending from Table 1). This is two-thirds the total elasticity estimated in the first panel, and suggests that about 70 percent of the decline in spending might be attributed to members dropping to zero utilization; the rest of the decline is a consequence of members using fewer services after copayments' increase than before. Table 6 performs the same calculation for different categories of care (we ignore categories where behavior at the extensive margin was not statistically different than zero): in general, behavior at the extensive margin explains a very significant portion of the overall price elasticity. This is a significant finding for it suggests that rather than all patients cutting back on some care, some patients cut back completely: the cost savings of greater cost-sharing are the consequence of this behavior.

\section{Robustness Checks}

In Table 7 we examine the robustness of our results to three alternative specifications. In the first specification, we ignore information from the window just before and just after the policy change (that is, we exclude June and July, 2008). We did this to examine the concern that patients may be stockpiling drugs, or seeking care, in anticipation of the policy change. Such behavior will cause us to overstate the price elasticity of demand for it accentuates the reduction

\footnotetext{
${ }^{5}$ Note that if all members had positive spending pre-reform, and if (pre-reform) spending for the average member were the same as spending for a person who dropped to zero utilization, then this exercise would generate the same elasticity as what we have estimated above. Of course, we have no way of validating this assumption, so this calculation is purely illustrative of the potential importance of these extensive responses.
} 
in utilization after the copayment increase (the increase in pre-policy use is accompanied by a reduction in post-policy use). The first panel of Table 7 shows that this fear is unfounded: the elasticities reported here are almost identical to those reported in Table 3, where we use all the data available to us. The use of prescription drugs is particularly susceptible to the concern about stockpiling, but we do not find any support for this actually happening.

Next, we restrict the analysis to the period just before and just after the policy change (that is, we keep data from April through September of 2008). The motivation for this specification is that the US financial markets collapsed in early October of 2008 and there was a rapid rise in recession-induced unemployment in late 2008 and 2009. We wanted to be sure that the price elasticity of demand that we are estimating was not partially confounded by these trends in the business cycle. While it is true that we have included income fixed-effects and very flexible year $\mathrm{x}$ month controls, there may still be income-specific trends in the data. To allay this concern we constructed Panel B of Table 7. The results are very similar to those in Table 3, so we are reassured that the business-cycle is not an alternative explanation for our results. One downside of this specification is that the loss of data also meant that we were unable to estimate a separate price elasticity of demand for hospital care (there was not enough variation in 6 months of the data to jointly identify all the fixed-effects that we have included and the effect of the copayment change, when it comes to a relatively rare event like hospital care).

Finally, in Panel C of Table 7, we coded the policy change as having occurred on January 1, 2008 (6 months before it actually happened) to verify that we obtained null effects from this placebo regression. Note that the estimated coefficients are never significant and much smaller in magnitude, thereby reassuring us that we have really picked up the effect of the policy change and not of a pre-existing differential trend.

\section{Discussion and Implications}

In the past, public insurance for our lowest income citizens has featured little patient copayment. This may reflect concerns both about affordability, and the ability of the poor to effectively manage their care in the face of marginal costs; in particular, the notion that the poor, facing unaffordable copayments, may cut back on necessary as well as unnecessary care. As public insurance subsidies have expanded to citizens above the poverty line, however, fiscal 
expediency suggests the use of some patient copayments. Yet concerns remain that copayments in this population may do more harm than good.

We have investigated this issue in the Commonwealth Care program in Massachusetts, the nation's largest expansion of publicly subsidized private insurance coverage and the model for the national Affordable Care Act. During our sample period there was a sizeable (in percentage terms) copayment change facing individuals with incomes between one and three times the poverty line. Using a unique set of claims data provided by the state we are able to study the impacts of this copayment change on overall utilization and on utilization of specific medical services.

Our results largely confirm the conclusions of the RAND Health Insurance Experiment. We find that health care demand is somewhat sensitive to copayments, but that the elasticity is small (-0.15 on average). We find that those who are chronically ill, and especially older individuals, have a higher elasticity of demand. But we also find no evidence for "offset effects" indicating that the reduced use of outpatient services has led to increased demand for hospital services. This is true even for the sickest patients in our sample, in contrast to our earlier study of elderly retired public sector workers in California. Our results suggest that concerns about 'offset effects' in poorer populations, while still possible, require substantially more evidence.

These results are subject to a number of caveats. In particular, these copayment changes are large in percentage terms but small in absolute dollar terms. It is possible that responses could differ for larger copayment changes or changes in coinsurance rates, which would induce larger patient cost-sharing than the copayment changes examined here. Moreover, we have not estimated pure own-price effects here. The decline in prescription drug use, for example, could come from the increase in prescription drug copayments or from the increase in office copayments, which could cause physicians to prescribe fewer drugs. Our aggregate elasticity is really the key measure for an overall rise in copayments, but it does not necessarily speak to the particulars of charging individually for these services. Future work could usefully address these limitations. 


\section{References}

Buntin, Melinda Beeuwkes \& Zaslavsky, Alan M., 2004. "Too much ado about two-part models and transformation?: Comparing methods of modeling Medicare expenditures," Journal of Health Economics, 23(3): 525-542.

Chandra, Amitabh, Jonathan Gruber, and Robin McKnight (2010a). "Patient Cost-Sharing and Hospitalization Offsets in the Elderly.” American Economic Review, 100(1): 193-213.

Chandra, Amitabh, Jonathan Gruber, and Robin McKnight (2010b). "Patient Cost Sharing in Low Income Populations." American Economic Review, 100(2): 303-08.

Chandra, A., Gruber, J. and McKnight, R. (2011). “The Importance of the Individual Mandate: Evidence from Massachusetts.”The New England Journal of Medicine, 364(4):293-295.

Charlson, M.E., P. Pompei, K.L. Ales, and C.R. McKenzie (1987). “A New Method of Classifying Prognostic Comorbidity in Longitudinal Studies: Development and Validation,” Journal of Chronic Disease 40(5): 373-83.

Donaldson, Cam “Top-ups for cancer drugs: can we kill the zombie for good?," BMJ 2008;337:a578, doi: 10.1136/bmj.a578 (Published 30 June 2008).

Evans RG, Barer ML, Stoddart GL, Bhatia V. Who are the zombie masters, and what do they want? Vancouver: Centre for Health Services and Policy Research, University of British Columbia, 1993.

Goldman, Dana and Tomas Philipson (2007). "Integrated Insurance Design in the Presence of Multiple Medical Technologies,” American Economic Review, 97(2): 427-432.

Hsu, John, Mary Price, Jie Huang, Richard Brand, Vicki Fung, Rita Hui, Bruce Fireman, Joseph P. Newhouse, and Joseph V. Selby (2006). "Unintended Consequences of Caps on Medicare Drug Benefits,” New England Journal of Medicine 354: 2349-2359.

Kaiser Commission on Medicaid and the Uninsured (2009). "The Uninsured: A Primer" Available at http://www.kff.org/uninsured/7451.cfm. Accessed on December 29, 2009.

Massachusetts Health Insurance Connector Authority (2008), "Report to the Massachusetts Legislature: Implementation of the Health Care Reform Law, Chapter 58 2006-2008, ” downloaded from http://www.mahealthconnector.org.

Manning, Willard G., Joseph P. Newhouse, Naihua Duan, Emmett B. Keeler, and Arleen Leibowitz (1987). "Health Insurance and the Demand for Medical Care: Evidence from a Randomized Experiment,” The American Economic Review 77(3): 251-277.

Newhouse, Joseph (1993). Free for All: Lessons from the RAND Health Insurance Experiment. Cambridge, MA: Harvard University Press. 
Tamblyn, Robyn, et. al (2001). "Adverse Events Associated With Prescription Drug CostSharing Among Poor and Elderly Persons,” JAMA 285(4), 24/31 January 2001, 421-429. 
Figure 1: Copayments for Generic Drugs

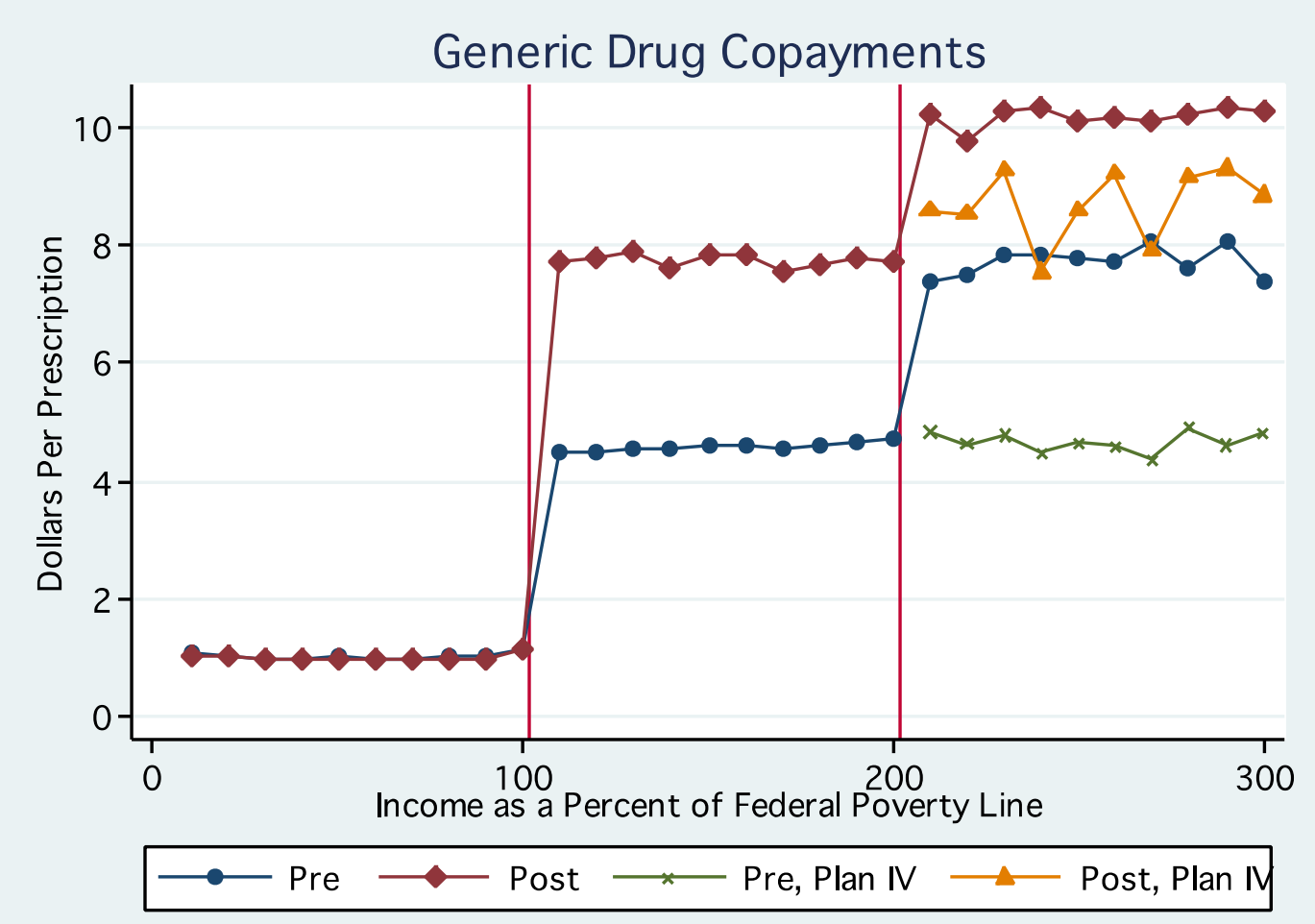


Table 1: Member Characteristics

\begin{tabular}{lcc}
\hline \hline & All Members & $\begin{array}{c}\text { Continuously Enrolled } \\
\text { (No plan switching) }\end{array}$ \\
\hline Age & 40.29 & 40.9 \\
Percent Male & 47 & 47 \\
Percent enrolled in Plan 1 & 52 & 52 \\
Percent enrolled in Plan 2 & 36 & 38 \\
Percent enrolled in Plan 3 & 10 & 9 \\
Percent enrolled in Plan 4 & 1 & 33 \\
Percent with Chronic Disease & 31 & \\
& & \\
Average Monthly Expenditure & & $\$ 358.8$ \\
Total & $\$ 384.6$ & $\$ 82.8$ \\
Hospitalizations & $\$ 91.3$ & $\$ 30.5$ \\
ER & $\$ 33.7$ & $\$ 43.9$ \\
Drugs & $\$ 44.5$ & $\$ 52.9$ \\
Office Visits & $\$ 55.3$ & $\$ 71.1$ \\
Outpatient & $\$ 75.7$ & $\$ 54.5$ \\
Lab & $\$ 58.2$ & $96.2 \%$ \\
& & $0.05 \%$ \\
Average FPL & $95.4 \%$ & 122,528 \\
Rate of Avoidable Hospitalizations & $0.06 \%$ & $1,866,212$ \\
Number of Members & 247,565 & \\
Number of Member-months & $2,842,492$ & \\
\hline \hline
\end{tabular}


Table 2: Copayment Changes by Percent of Federal Poverty Line of Member

\begin{tabular}{|c|c|c|c|c|}
\hline & $\begin{array}{l}\text { Plan 1: 0-100 } \\
\text { percent of FPL }\end{array}$ & $\begin{array}{l}\text { Plan 2: 100-200 } \\
\text { percent of FPL }\end{array}$ & $\begin{array}{l}\text { Plan 3: 200-300 } \\
\text { percent of FPL }\end{array}$ & $\begin{array}{l}\text { Plan 4: } 200-300 \\
\text { percent of FPL }\end{array}$ \\
\hline \multicolumn{5}{|c|}{ Copayments for Hospital Inpatient Admission } \\
\hline Oct '06- Jun '08 & $\$ 0$ & $\$ 50$ & $\$ 250$ & $\$ 50$ \\
\hline Jul '08-present & $\$ 0$ & $\$ 50$ & $\$ 250$ & $\$ 250$ \\
\hline \multicolumn{5}{|c|}{ Copayments for Emergency Room visits } \\
\hline Oct '06- Jun '08 & $\$ 3$ & $\$ 50$ & $\$ 75$ & $\$ 50$ \\
\hline Jul '08-present & $\$ 3$ & $\$ 50$ & $\$ 100$ & $\$ 100$ \\
\hline \multicolumn{5}{|c|}{ Copayments for Outpatient Surgery } \\
\hline Oct '06- Jun '08 & $\$ 0$ & $\$ 50$ & $\$ 100$ & $\$ 50$ \\
\hline Jul '08-present & $\$ 0$ & $\$ 50$ & $\$ 125$ & $\$ 125$ \\
\hline \multicolumn{5}{|c|}{$\begin{array}{l}\text { Copayments for Office Visits } \\
\text { (Primary Care/ Specialist) }\end{array}$} \\
\hline Oct '06- Jun '08 & $\$ 0 / \$ 0$ & $\$ 5 / \$ 10$ & $\$ 10 / \$ 20$ & $\$ 5 / \$ 10$ \\
\hline Jul '08-present & $\$ 0 / \$ 0$ & $\$ 10 / \$ 18$ & $\$ 15 / \$ 22$ & $\$ 15 / \$ 22$ \\
\hline \multicolumn{5}{|c|}{$\begin{array}{l}\text { Copayment for Prescription Drugs } \\
\text { (Generics/ Formulary/ Non-Formulary Retail) }\end{array}$} \\
\hline Oct '06- Jun '08 & $\$ 1 / \$ 3$ & $\$ 5 / \$ 10 / \$ 30$ & $\$ 10 / \$ 20 / \$ 40$ & $\$ 5 / \$ 10 / \$ 30$ \\
\hline Jul '08-present & \$1/ \$3 & $\$ 10 / \$ 20 / \$ 40$ & $\$ 12.50 / \$ 25 / \$ 50$ & $\$ 12.50 / \$ 25 / \$ 50$ \\
\hline \multicolumn{5}{|c|}{$\begin{array}{l}\text { Average Copayment Change } \\
\text { (across all services) }\end{array}$} \\
\hline Oct '06- Jun '08 & $\$ 0.79$ & $\$ 6.53$ & $\$ 13.70$ & $\$ 6.53$ \\
\hline Jul '08-present & $\$ 0.79$ & $\$ 10.85$ & $\$ 17.26$ & $\$ 17.26$ \\
\hline Increase & 0 percent & 51 percent & 23 percent & 97 percent \\
\hline
\end{tabular}

Note: Prior to July 2008, there were two plan types for members whose income was between 200 and 300 percent of the FPL (Plans 3 and 4). Plan 4 was discontinued in July 2008 and its members were enrolled in Plan 3. Throughout this period, the copayment for emergency room use is waived if the patient is admitted to the hospital. To calculate average copayments, we weighted copayments for each service (hospitalizations, ER use, prescription drugs) by its pre-reform utilization (pre July 2008 utilization). Source: The Massachusetts Health Insurance Connector Authority (2008). 
Table 3: GLM Estimates of the Effect of Copayment Increases on Healthcare Spending, All Patients

\begin{tabular}{|c|c|c|c|c|c|c|}
\hline $\begin{array}{c}\text { Total } \\
\text { Spending }\end{array}$ & $\begin{array}{l}\text { Hospital } \\
\text { Spending }\end{array}$ & $\begin{array}{c}\text { ER } \\
\text { Spending }\end{array}$ & $\begin{array}{l}\text { Outpatient } \\
\text { Spending }\end{array}$ & $\begin{array}{l}\text { Office Visit } \\
\text { Spending }\end{array}$ & Rx Spending & $\begin{array}{c}\text { Lab } \\
\text { Spending }\end{array}$ \\
\hline
\end{tabular}

Panel A: All Patients

$\begin{array}{cccccccc}\ln (\text { Copay) } & -0.152 & -0.116 & -0.203 & -0.201 & -0.144 & -0.121 & -0.269 \\ & (0.063) & (0.241) & (0.147) & (0.118) & (0.049) & (0.072) & (0.087) \\ \mathrm{N} & 9644 & 9644 & 9644 & 9644 & 9644 & 9644 & 9644\end{array}$

Note: Each number in the table is an elasticity that comes from a separate GLM regression. Dependent variable is Total Monthly Healthcare Expenditure per member per month. Standard errors are clustered on member, and explanatory variables include percent of FPL fixed-effects, and year*month indicators. 
Table 4: GLM Estimates of the Effect of Copayment Increases on Medical Spending, by Type of Patient

$\begin{array}{lcccccccc} & \text { All Patients } & \begin{array}{c}\text { No Chronic Disease } \\ \text { (Charlson=0) }\end{array} & \begin{array}{c}\text { Chronic Disease } \\ \text { (Charlson=1+) }\end{array} & \text { Females } & \text { Males } & \text { Age 19-35 } & \text { Age 55-65 } \\ \ln (\text { Copay) } & -0.152 & -0.178 & -0.213 & -0.154 & -0.195 & -0.154 & -0.333 \\ & (0.063) & (0.067) & (0.098) & (0.075) & (0.116) & (0.113) & (0.117) \\ \text { N } & 9644 & 9619 & 9590 & 9638 & 9593 & 9219 & 9547\end{array}$

\footnotetext{
Note: Each number in the table is an elasticity that comes from a separate GLM regression. Dependent variable is Total Monthly Healthcare Expenditure per member per month. Standard errors are clustered on member, and explanatory variables include percent of FPL fixed-effects, year*month indicators.
} 
Table 5: GLM Estimates of the Effect of Copayment Increases on Spending, Chronically Sick Members

$\begin{array}{cccccccc} & \begin{array}{c}\text { Total } \\ \text { Spending }\end{array} & \begin{array}{c}\text { Hospital } \\ \text { Spending }\end{array} & \begin{array}{c}\text { ER } \\ \text { Spending }\end{array} & \begin{array}{c}\text { Outpatient } \\ \text { Spending }\end{array} & \begin{array}{c}\text { Office Visit } \\ \text { Spending }\end{array} & \text { Rx Spending } & \begin{array}{c}\text { Lab } \\ \text { Spending }\end{array} \\ \ln \text { (Copay) } & -0.213 & -0.387 & -0.019 & -0.319 & -0.154 & -0.121 & -0.325 \\ & (0.098) & (0.365) & (0.228) & (0.167) & (0.081) & (0.088) & (0.128) \\ N & 9590 & 9590 & 9590 & 9590 & 9590 & 9590 & 9590\end{array}$

Note: Each number in the table is an elasticity that comes from a separate GLM regression. Dependent variable is Total Monthly Healthcare Expenditure per member per month. Standard errors are clustered on member, and explanatory variables include percent of FPL fixed-effects, and year*month indicators. 
Table 6: OLS Estimates of the Effect of Copayment Increases on any Spending (Extensive Margin Results), All Patients

\begin{tabular}{|c|c|c|c|c|c|c|c|}
\hline & $\begin{array}{c}\text { Any } \\
\text { Spending }\end{array}$ & $\begin{array}{l}\text { Any Hospital } \\
\text { Spending }\end{array}$ & $\begin{array}{l}\text { Any ER } \\
\text { Spending }\end{array}$ & $\begin{array}{c}\text { Any } \\
\text { Outpatient } \\
\text { Spending }\end{array}$ & $\begin{array}{c}\text { Any Office } \\
\text { Visit Spending }\end{array}$ & $\begin{array}{l}\text { Any Rx } \\
\text { Spending }\end{array}$ & $\begin{array}{l}\text { Any Lab } \\
\text { Spending }\end{array}$ \\
\hline $\ln$ (Copay) & $\begin{array}{l}-0.050 \\
(0.009)\end{array}$ & $\begin{array}{l}-0.0002 \\
(0.002)\end{array}$ & $\begin{array}{l}-0.001 \\
(0.002)\end{array}$ & $\begin{array}{l}-0.001 \\
(0.005)\end{array}$ & $\begin{array}{l}-0.019 \\
(0.007)\end{array}$ & $\begin{array}{l}-0.067 \\
(0.009)\end{array}$ & $\begin{array}{l}-0.023 \\
(0.005)\end{array}$ \\
\hline $\mathrm{N}$ & 9644 & 9644 & 9644 & 9644 & 9644 & 9644 & 9944 \\
\hline $\begin{array}{l}\text { Average Spending } \mid \\
\text { Spending }>0\end{array}$ & $\$ 788$ & $\$ 5,711$ & $\$ 1,064$ & $\$ 725$ & $\$ 210$ & $\$ 150$ & $\$ 376$ \\
\hline $\begin{array}{l}\text { Implied Elasticity } \\
\text { from Extentive Margin }\end{array}$ & -0.10 & - & - & - & -0.075 & -0.228 & -0.159 \\
\hline
\end{tabular}

Note: Each number in the table is the percentage point change in the probability of having any medical spending. Each estimate comes from a separate OLS regression that is estimated at the percent of FPL x month level. Dependent variable is the fraction of the cell that had any utilization. Standard errors are clustered on member, and explanatory variables include percent of FPL fixed-effects, and year*month indicators. The implied elasticity from the extensive margin is the price elasticity of demand that would arise from behavior at the extensive margin. Empty cells are those where the effect at the extensive margin is not statistically different than zero. 


\begin{tabular}{|c|c|c|c|c|c|c|}
\hline $\begin{array}{c}\text { Total } \\
\text { Spending }\end{array}$ & $\begin{array}{l}\text { Hospital } \\
\text { Spending }\end{array}$ & $\begin{array}{c}\text { ER } \\
\text { Spending }\end{array}$ & $\begin{array}{l}\text { Outpatient } \\
\text { Spending }\end{array}$ & $\begin{array}{l}\text { Office Visit } \\
\text { Spending }\end{array}$ & Rx Spending & $\begin{array}{c}\text { Lab } \\
\text { Spending }\end{array}$ \\
\hline
\end{tabular}

Panel A: Omit Policy Change Window

(exlude June/July 2008; $n=8840$ )

$\begin{array}{llllllll}\ln \text { (Copay) } & -0.189 & -0.192 & -0.324 & -0.230 & -0.115 & -0.127 & -0.288 \\ & (0.070) & (0.273) & (0.155) & (0.129) & (0.054) & (0.080) & (0.095)\end{array}$

Panel B: Restrict to Policy Change Window

(retain April to September 2008; n=2412))

$\begin{array}{cccccccc}\ln (\text { Copay) } & -0.198 & \text { insufficient } & -0.061 & -0.220 & -0.240 & -0.127 & -0.276 \\ & (0.085) & \text { data } & (0.222) & (0.134) & (0.062) & (0.060) & (0.088)\end{array}$

Panel C: Falsify Policy change by changing date (set policy change to Jan 2008 and keep observations through Jun 2008; n=4820)

$\begin{array}{lccccccc}\ln (\text { Copay) } & 0.092 & 0.374 & 0.064 & -0.034 & 0.125 & -0.051 & 0.041 \\ & (0.093) & (0.496) & (0.209) & (0.162) & (0.078) & (0.092) & (0.115)\end{array}$

Note: Each number in the table is an elasticity that comes from a separate GLM regression. Dependent variable is Total Monthly Healthcare

Expenditure per member per month. Standard errors are clustered on member, and explanatory variables include percent of FPL fixed-effects, and year*month indicators. 